\title{
Hydrocephalus and Danty Walker Cyst, a Study of 33 Cases in Friendship Hospital Sino-Guinea of Kipe in Guinea
}

\author{
Ibrahima Sory Souare ${ }^{1}$, Luc Kezely Beavogui ${ }^{2}$, Soriba Naby Camara ${ }^{3}$, Sneha Ballah ${ }^{4}$, \\ Naby Daouda Camara ${ }^{5}$, Amara Cisse ${ }^{6}$ \\ ${ }^{1}$ Department of Neurosurgery Faculty of Medecine, University Gamal Abdel Nasser of Conakry, Conakry, Guinea \\ ${ }^{2}$ Department of Neurosurgery, Faculty of Medecine, University Gamal Abdel Nasser of Conakry, Conakry, Guinea \\ ${ }^{3}$ Department of Visceral Surgery, Faculty of Medecine, University Gamal Abdel Nasser of Conakry, Conakry, Guinea \\ ${ }^{4}$ Department of General Surgery, University of Mauritius, Mauritius, Mauritius \\ ${ }^{5}$ Department of General Surgery Faculty of Medecine, University Gamal Abdel Nasser of Conakry, Conakry, Guinea \\ ${ }^{6}$ Department of Neurology, Faculty of Medecinel, University Gamal Abdel Nasser of Conakry, Conakry, Guinea
}

\section{Email address:}

souareis@yahoo.fr (I. S. Souare), csoribanaby@yahoo.com (S. N. Camara)

\section{To cite this article:}

Ibrahima Sory Souare, Luc Kezely Beavogui, Soriba Naby Camara, Sneha Ballah, Naby Daouda Camara, Amara Cisse. Hydrocephalus and Danty Walker Cyst, a Study of 33 Cases in Friendship Hospital Sino-Guinea of Kipe in Guinea. Advances in Surgical Sciences.

Vol. 4, No. 4, 2016, pp. 18-22. doi: 10.11648/j.ass.20160404.11

Received: July 11, 2016; Accepted: July 28, 2016; Published: September 2, 2016

\begin{abstract}
Dandy-Walker Malformations (or cysts) are developmental malformations in which the Cerebellar Vermis may be partially or completely absent, with resulting dilation of the 4th Ventricle forming a "Cyst". It is thought that the defect arises from abnormal embryogenesis of the roof of the 4th Ventricle. A milder form is termed the "Dandy-Walker Variant". This disorder may account for approximately $5 \%$ to $10 \%$ of cases of Ventriculomegaly. This study aims to reveal particular cases of Danty Walker Cases when associated with hydrocephalus, in the African context. It is a retrospective and descriptive study carried out at the Neurosurgery department of the Friendship hospital of Kipe in Guinea for 36 months, from June 2012 to August 2015. Of the 120 patients hospitalized for hydrocephalus, 32 cases have exhibited the Dandy Walker cyst. Among the 32 patients, 15 were of male and 17 were of female gender at a sex ratio $(\mathrm{H} / \mathrm{F})$ of $0.88 ; 1$. The dominant clinical symptoms that were observed in our subjects were macrocrania ( 32 cases), bulging fontanelle ( 25 cases), sunsetting eyes (19 cases). The degree of macrocrania was noted to be minimal in 1 case only, mild in 5 cases, moderate in 8 cases, and excessive in 18 cases. Furthermore, CT scan results showed evidence of triventricular hydrocephalus in 14 cases, and tetraventricular hydrocephalus in 18 cases. The anatomical variations encountered among others were, MDW in 15 cases, DWV in 11 cases et DWC in 6 cases. The calculated Evan's index was equal to 0.3 in 6 patients and greater than 0.3 in 26 patients. The operative techniques most commonly widely conducted were DVP (16 caes), VCS (13 cases) and DKP (3 cases). The average duration of hospitalization was 20 days with extreme range of 1 to 49 days. The post operative period was uneventful in 16 cases, clinically unchanged in 5 cases and post operative deaths were reported in 11 cases. The principal causes of death originated from the presence co-existing infections, respiratory distress, anemia and malarial sickness.
\end{abstract}

Keywords: Hydrocephalus, Dandy Walker, Cyst, Friendship Hospital of Kipe

\section{Introduction}

Dandy-Walker malformation (DWM) is a rare congenital disorder which involves the posterior cerebral fossa. Generated between the 7th and 12th week of gestation, it is characterised by: a hypoplasia of the vermis, a communicating cyst between the 4 th ventricle and posterior fossa, abnormally high position of the straight sinus, torcular herophili, and tentorium, and an anteroposterior enlargement of the posterior fossa. [1]

Its incidence is noted to be betwen $1 / 25000$ and $1 / 35000$ per live births and is often associated with a hydrocephalus. [1]. The prevalence of hydrocephalus is 0.82 per 1000 live 
births in the occidental region [2], and at $1.5 \%$ in Africa [2]. DWMs are often linked to genetic anomalies, cerebral malformations (heterotropy of grey matter, meningocele, agenesis of the corpus callosum) or systemic defects (cardiac defects, skeletal malformations, intestinal malformations, urogenital or facial defects) which can affect the nervous system $[3,4]$.

Hydrocephalus associated with DWM in infants is a pathology which can be observed at any age, in which the etiologies are multiple and often modulated by genetic factors, and/or environmental factors. It can also ensue as a consequence of congenital malformations, infections, trauma, disequilibrium in cerebrospinal fluid (CSF) pressure, vascular lesions [2]. The imaging techniques available for antenatal diagnosis used are ultrasound, magnetic resonance imagin (MRI), CT imaging, for establishing a precise anatomical mapping, and to locate any of the associated malformations: agenesis of the corpus callosum, occipital meningocele, meningomyelocele, Joubert syndrome, WalkerWalburg syndrome, Arnold Chiari [5].

The management of hydrocepahlus associated with Dandy Walker malformation is fundamentally surgical; fenestration of the cyst through its opening into the subarachnoid space, followed by a ventriculoperitoneal derivation. More recently, endoscopic ventriculocisternomy with a partial coagulation of the choroid plexus is a widely recommended procedure [6].

\section{Methodology}

\subsection{Patients and Type of Study}

It is a retrospective study of descriptive type carried out over a period of 38 months from 26 june 2012 to 26 august 2015 in the neurosurgical service at the Friendship hospital in SinoGuinea. The clinical data collected included both the preoperative data, postoperative results.

\subsection{Inclusion Criteria}

The patients selected for the study had a hydrocephalus which was associated with a Dandy walker cyst confirmed by $\mathrm{CT}$ and/or transfontanellar ultrasound imaging.

\subsection{Investigations}

The data collected for the study were frequency, age, sex, motive for medical consult, time delay for admission, clinical studies, degree of macrocrania, paraclinical tests performed and treatment methods.

\section{Results}

We have assembled a total of 597 hospitalized patients in the neurosurgical service during the period of study, with 120 cases of hydrocephalus among which 32 cases were associated with DWM.

The study was carried out on 17 female 15 male subjects, at sex ratio of 0.88

In our study, the most common age group was between 29 days to 12 months (66\%), followed by age group between 13 months to 3 years $(19 \%), 4$ to 7 years $(6 \%), 8$ to 10 years (3\%), 11 to 14 years $(3 \%)$ and $0-28$ days $(3 \%)$. The delay for admission was 15 days in 15 cases, 31 days in 7 cases and 46 days in 10 cases.

Table 1. Frequency for motive for consultation.

\begin{tabular}{lll}
\hline Motive for consultation & Number of cases & Percentage \\
\hline Macrocrania & 32 & 100 \\
Fever & 10 & 31.25 \\
Bulging fontanel & 25 & 78.12 \\
Vomiting & 3 & 9.37 \\
Irritability & 8 & 25 \\
Seizures & 6 & 18.75 \\
Gait and posture disturbance & 1 & 3.12 \\
Umbilical lesion & 1 & 3.12 \\
Refuse to breastfeed & 1 & 3.12 \\
Delay in walking & 2 & 6.25 \\
Others $\left(^{*}\right)$ & 4 & 12.75 \\
\hline
\end{tabular}

*: Cough, Somnolence, Weight, erythema in buttock area

Table 2. Classification of cases according to degree of macrocrania.

\begin{tabular}{lll}
\hline Degree of Macrocrania & Number & Percentage (\%) \\
\hline Minimal & 1 & 3 \\
Mild & 5 & 16 \\
Moderate & 8 & 25 \\
Excessive & 18 & 56 \\
Total & 32 & 100 \\
\hline
\end{tabular}

Table 3. Frequency according to Imaging result.

\begin{tabular}{lll}
\hline ETF/TDM & Number of cases & Percentage \\
\hline Triventricular Hydrocephalus & 14 & 43.75 \\
Tetraventricular Hydrocephalus & 18 & 56.25 \\
Cerebral atrophy & 3 & 9.37 \\
Anencephaly & 1 & 3.12 \\
Hydroma & 1 & 3.12 \\
Abscess & 3 & 9.37 \\
Supra cerebellar cyst & 1 & 3.12 \\
Stenosis of aqueduct of Sylvius & 9 & 28.12 \\
\hline
\end{tabular}

Table 4. Number of cases according to the anatomical defect subtype.

\begin{tabular}{lll}
\hline Anatomical defect & Number of cases & Percentage (\%) \\
\hline MDW & 15 & 47 \\
DWV & 11 & 34 \\
DWC & 6 & 19 \\
Total & 32 & 100 \\
\hline
\end{tabular}

Table 5. Classification of patients according to degree of fronto-occipital enlargement.

\begin{tabular}{lll}
\hline & Number of cases & Percentage (\%) \\
\hline Minimal & 3 & 9.37 \\
Moderate & 2 & 6.25 \\
Excessive & 17 & 53.12 \\
Extreme & 7 & 21.87 \\
\hline
\end{tabular}

Table 6. Classification of interventional technique performed on the patients.

\begin{tabular}{lll}
\hline Technique & Number of cases & Percentage (\%) \\
\hline DVP & 16 & 50 \\
VCS & 13 & 41 \\
DKP & 3 & 9 \\
Total & 32 & 100 \\
\hline
\end{tabular}


Table 7. Classification of patients according to post operative health condition.

\begin{tabular}{lll}
\hline Evolution & Number of cases & Percentage (\%) \\
\hline Improved & 16 & 50 \\
Unchanged & 5 & 15.6 \\
Deaths & 11 & 34.4 \\
Total & 32 & 100 \\
\hline
\end{tabular}

The principal morbidities dominating the clinical picture were infection (37\%), malaria (27\%), anemia and respiratory distress (18\%)

Table 8. Classification of patients according to duration of hospital stay.

\begin{tabular}{lll}
\hline Duration of hospital stay (days) & Number & Percentage \\
\hline $1-14$ & 21 & 66 \\
$15-22$ & 6 & 19 \\
$23-30$ & 1 & 3 \\
$31-49$ & 4 & 12 \\
Total & 32 & 100 \\
\hline
\end{tabular}

Average: 19.7; Extreme range: 1-49

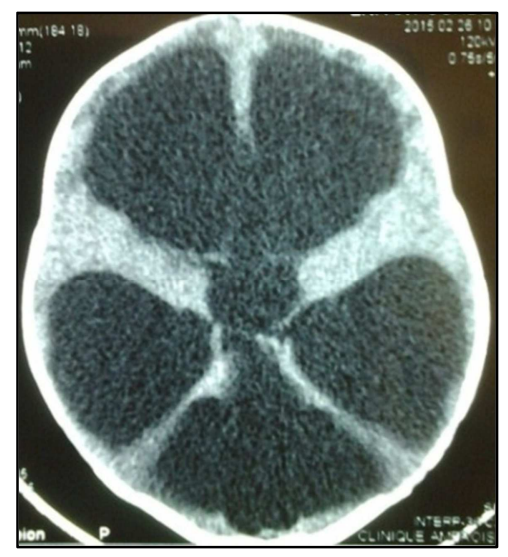

Fig. 1. CT imaging of the brain showing hydrocephalus with Dandy Walker cyst.

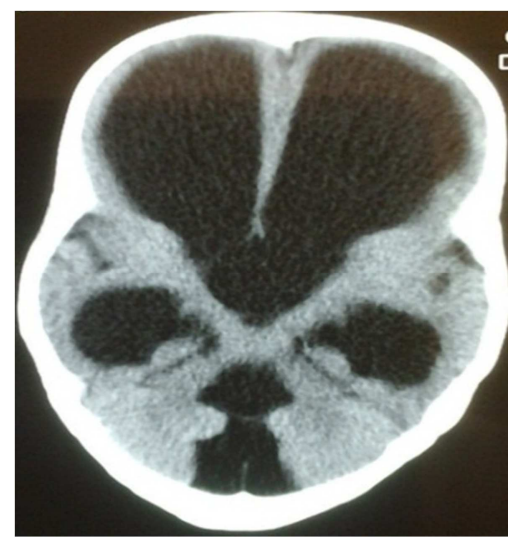

Fig. 2. Brain CT image reveals a dilated ventricle of Dandy Walker variant type.

\section{Discussion}

\subsection{Clinical Incidence}

DWM is a rare congenital malformation involving the posterior cerebral fossa at an incidence of $1 / 25000$ to $1 / 35000$ per births.
During our study, we have observed among 120 cases presenting with hydrocephalus in our service, 32 cases of hydrocephalus with DW cyst (27\%).

The incidence is noted to vary for each country as reported by Adjenou. K. V et al [9] in 2012 in Togo at an incidence of $5.45 \%$. The incidence is recognized to be comparatively lower because of the presence of diverse NGOs (Nongovermental organisations) which are involved in the early management of pediatric hydrocephalus patients.

\subsection{Age and Sex}

The average age of the patients at presentation was 20.17 months with a range extreme of 22 days to 14 years. The age variation is due to the non specific age at presentation in the pediatric population. In our series, we have noted a female gender predominance with 17 cases compared to 15 male cases, at a male-to-female sex ratio of $0.88 \%$. Similarly, in 2010 in Morocco, Basraoui et al. [7] have reported a female predominance without any valid explanation being held for this predominance. However, in Nigeria, male predominance at a sex ratio of 1.4 and average age of 8.7 months (52.77\%) was reported, while in Togo, authors had a sex ratio of 1.5 and average age of 19 months [9], also, with no valid explanation for the gender predominance.

The delay in consultation was and/or late clinical presentation of the cystic malformations are both directly responsible for the delayed diagnosis in the majority of our subjects.

\subsection{Motive for Seeking Medical Consult}

Macrocrania was the leading reason to urge patients to seek medical consult in our series, followed by bulging fontanel $(78.12 \%)$, fever $(31.25 \%)$, irritability $(25 \%)$, and seizures $(18.75 \%)$. The delay in diagnosis is marked by sociocultural as well as economic conditions which compel the parents to opt for traditional methods of treatment, resulting in a high prevalence of macrocrania as observed in our patients.

\subsection{Admission Delay}

The average delay in admission was recorded to be 18.5 days with extreme range of 1 to 46 days. The reason for the relatively long delay in admission can be traced back to the sensitization provided by the media towards our population in the aim of educating the society on the proper management of children suffering from hydrocephalus.

\subsection{Physical Signs}

Macrocrania was the most obvious sign in all cases, followed by bulging and tense fontanel $(78.12 \%)$, sunsetting eyes $(59.37 \%)$, prominent veins on the surface of the skull (43.75\%) and craniofacial disproportion (40.62\%).

The signs represent the consequence of intracranial hypertension which causes compression of the cerebral parenchyma against the skull. Other signs provoked by associated diseases were loss in skin turgor secondary to dehydration $(6.25 \%)$, tonic-clonic seizures $(3.12 \%)$, and ataxia $(3.12 \%)$. 


\subsection{Degree of Macrocrania}

Macrocrania was recorded in all our patients at time of admission and was described as: excessive with a head circumference $\geq 16 \mathrm{~cm} \quad(56 \%)$, moderate with head circumference between $10-15 \mathrm{~cm}(25 \%)$, mild with head circumference between $6-10 \mathrm{~cm}$ in $(5 \%)$, minimal with head circumference $1-5 \mathrm{~cm}>$ upper limit of normal. In our series, it is crucial to precise that only 1 subject was found to have normal head circumference. The absence of macrocrania presentation is most likely explained by the precocious admission of the patient, given that the first sign is usually bulging of the fontanel, despite noting that the latter is not often the primary reason for consultation.

\subsection{Imaging Results}

CT imaging, reliable for confirming the diagnosis of hydrocephalus with DWM, was performed for all subjects in our study. The results showed 18 cases of tetraventricular hydrocephalus $(56.25 \%)$, and 14 cases with triventricular hydrocephalus (43.75\%). Adjenou. K. V et al. similarly reported a predominance of tetraventricular hydrocephalus (57.14\%) and triventricular hydrocephalus (38.1\%) in 2012 [9], while BA M. C et al. showed a higher percentage of tetraventricular hydrocephalus $(76.19 \%)$ with a lower percentage of triventricular hydrocephalus (19.04\%) [8].

We have subsequently observed the associated lesions including stenosis of aqueduct of Sylvius (28.12\%), cerebral atrophy $(9.37 \%)$, cerebral abscess $(9.37 \%)$, supracerebellar cyst $(3.12 \%)$, hydroma $(3.12 \%)$ and anencephaly (3.12\%). The possibility of establishing an etiological diagnosis improves both the management and prognosis of the patients. None of our patients could benefit from MRI technique due to its high cost and uncommon use in our setting.

\subsection{Anatomical Forms}

In our study on 32 pediatric patients with hydrocephalus presenting with DW cyst, 15 cases presented with DWM (47\%), 11 cases with Dandy Walker variant (34\%) and 6 cases of complex Dandy Walker (19\%). In 2013, Sanoussi S. et al [3] have published a series of studies on 144 patients with $46.57 \%$ of DWM, $14.58 \%$ of DW variant, and $38.88 \%$ of complex DW with megacisterna magna cyst.

\subsection{Evan's Index}

Evan's index was calcculated in all patients in preoperative period, and revealed that 26 cases $(81.25 \%)$ had an elevated index value. Ventriculomegaly associated with an augmented CSF volume in the skull, was noted in 3 cases $(9.36 \%)$. A normal index would signify an early presentation in the disease course. Sanoussi et al. [3] reported a comparatively higher percentage of ventriculomegaly (63.19\%), and Evan's index $\geq 0.4$ at an average preoperative Evan's value of 0.42 .

\subsection{Frontal and Occipital Horn Width Ratio}

In our study, the Frontal and occipital horn width ratio was evaluated in 29 out of 32 patients and classified as: Minimal $(0.35-0.55)$ in $9.37 \%$, moderate $(0.60-0.75)$ in $6.25 \%$, excessive $(0.80-1.05 \%)$ in $53.12 \%$, extreme $(\geq 1.10)$ in $21.87 \%$. The ratio could not be obtained in 3 patients $(9.37 \%)$ due to the presence of abscess preventing measurement of frontooccipital, biparietal and biocciptal parameters.

\subsection{Treatment}

The principle of every intervention is to connect all the ventricles to allow reabsorption of the CSF. All the patients have benefitted from surgical treatment, with symptomatic intervention provided by venticuloperiotenal shunting in 16 patients $(50 \%)$ for managing communicating hydrocephalus $[10,11]$.

Ventriculocisternostomy with cauterization of choiroidal plexus was conducted in 13 patients $(41 \%)$ for obstructive hydrocephalus and a cystoperitoneal derivation was provided in 3 patients $(9 \%)$. The VPD was the most preferred used surgical method, especially, known to produce good quality of results and relative simplicity of procedure.

\subsection{Post Operative Condition}

In our study, only $50 \%$ of the subjects have shown improvement, 5\% remaining in a stationary clinical state, and, 11 post operative deaths noted $(34.37 \%)$. Our results show that the prognosis of Hydrocephalus with associated DWM is favorable only in the shortterm with early and careful management and no comorbidities associated $[12,13]$.

The decrease in number of deaths had a significant link with the number of comorbidities present. Based on this finding we could conclude that the patients with 1-3 coexisting comorbid conditions were among the cases which showed the greatest post operative improvement. However, the mortality rate was high in the patient groups who had 4-6 comorbid conditions.

\subsection{Morbidity}

In our series, the causes of death were related to infection in 4 cases $(27 \%)$, followed by anemia in 3 cases $(27 \%)$, respiratory distress in 2 cases (18\%), malaria in 2 cases (18\%). The daily unfavorable hygienic living conditions and nutrition issues faced by this poverty-stricken population together favor the development of diseases which decrease the quality of life of children. [14, 15]

\subsection{Duration of Hospital Stay}

The average duration of hospital stay was 19.7 days with extreme range of 1 to 49 days. Other studies recorded a superior average value when compared to to our mean average hospital stay, as the procedure was conducted with meticulous care in well controlled environment and skilled personnel. 


\section{Conclusion}

DWM is a congenital malformation involving the posterior cerebral fossa and is generated between the 7th and 12th gestation week. Hydrocephalus with associated DWM is common in Guinea, an accurate estimate of the incidence cannot be calculated, owing to the lack of access to competent diagnostic technology. The clinical picture was mostly dominated by signs of hydrocephalus in the pediatric patient such as macrocrania, bulging fontanel, distended veins of the skull, sunsetting eyes. Other signs such as cutaneous lesions, buccal candidiasis, ataxia, tonic clonic seziures, decrease in IQ and shrunken skin folds were also frequently seen. CT of the brain and/or ultrasound allowed us to clearly identify the cyst communicating with the 4th ventricle in the posterior fossa, whether or not it was associated with a hypoplasia of the vermis, or a dilatation of the ventricles with enlarged anteroposterior posterior fossa, and interpret the values of the representative indices (Evan's, frontal occipital width ratio) to closely watch the evolution of the hydrocephalus. It is of critical importance to recognize the risks affecting the outcome of the surgical procedures, as the surgical outcome would have been more favorable if the procedure was conducted earlier in a number of patients. It is also observed that the results of $\mathrm{VCS} / \mathrm{CPC}$, DVP remain satisfactory when performed without delay in carefully selected patients. Timely admission and management are hampered by sociocultural taboo and economic factors which still exist today, and adversely affect the outcome of these patients.

\section{Conflict of Interest Statement}

The authors declare that there is no conflict of interest with any financial organization or corporation or individual that can inappropriately influence this work.

\section{References}

[1] Klein. O, Khan-Pierre. A. La Malformation de Dandy-Walker J. Neurochirurgie (Paris). 2006; 52: 347-356.

[2] Kone. M. A. Apport de l'échographie et de la Tomodensitométrie dans la prise en charge des hydrocéphalies au CHME-BAMAKO Thèse de doctorat en Médecine université de Bamako 2011: 1-60.

[3] Sanoussi. S; Kelani. A; Chaibou. M. S; Baoua. M; Assoumane. I; Sani. R. M. Dandy - Walker malformations:
Diagnosis features and endoscopic management African Journal of Neurological Sciences (Niger) 2013; 32 (1): 1-13.

[4] Rouviere H, Delmas A. Système nerveux central Anatomie humaine; descriptive; topographique et Fonctionnelle, Paris: Masson, $15^{\text {ème }}$ édition 2002; IV, 217

[5] Cherif-Ech. N; Kettani El, Benelhosni K., Youssoufi L. El; Fikri. M, Hassani. M. R. El, Chakir. N; Jiddane. M Malformation de Dandy-Walker variant, J. Frad Feuillets de radiologie (Maroc) 2010; 50: 103-104

[6] Garel. C; Guibaud. L Malformation de Dandy- Walker et autres malformations kystique de la fosse cérébrale postérieure Mt. Médecine de la Reproduction, Gynécologie endocrinologie, (France). 2010; 12 (2): 103-105.

[7] Basraoul. D, Jalal. H, Zougari. A, Essadki. O, Ousehal. A Imagerie de la malformation de Dandy Walker chez l'enfant (à propos de 18 cas), JFR-Marrakech (Maroc), congrès 2010; 951 .

[8] Ba M C; Kpelao. S; Thioub. M; Kouara. M; Thiam. A. B; Ndoye. N; Sackho. Y; Badiane S. B Hydrocéphalie postméningitique du nourrisson à Dakar, African Journal of Neurological Sciences, (DAKAR). 2012; 31, (1): 8-14.

[9] Adjenou K. V; Amadou. A. A; Adiogo. A. M. Y; Agoda K. L; Sonhaye. L; Adambounou. K. F; Ahoulou. A; Belo. M; N'Dakena. K; Egnonglo ETF et TDM dans le diagnostic des hydrocéphalies chez l'enfant à Lomé, J. Rech. Sci. Univ. Lomé, (Togo). 2012; Série D, 14 (2): 3945

[10] Barkovich A, Kjos B, Norman D, et al. Revised classification of posterior fossa cysts and cystlike malformations based on the results of multiplanar MR imaging. AJNR 1989; 10: 977988 .

[11] Bordarier C, Aicardi J. Dandy-Walker syndrome and agenesis of the cerebellar vermis: diagnostic problems and genetic counseling. Dev Med Child Neurol 1990: 32 (4): 285-294.

[12] Ecker J Shipp T, Bromley B, et al. The sonographic diagnosis of Dandy-Walker and Dandy-Walker variant: associated findings and outcomes. Prenat Diagn 2000; 20 (4): 328-32.

[13] Grinberg I, Northrup H, Ardinger H, et al. Heterozygous deletion of the linked genes ZIC1 and ZIC4 is involved in Dandy-Walker malformation. Nature Genetics 2004; 36: 1053-1055.

[14] Kalidasan V, Carroll T, Allcutt D. et al. The Dandy-Walker syndrome-a 10 year experience of its management and outcome. Eur J Pediatr Surg 1995: 5 suppl 1: 16-18.

[15] Kolble N, Wisser J, Kurmanavicius J, et al. Dandy-Walker malformation: prenatal diagnosis and outcome. Prenat Diagn 2000; 20 (4): 318-327. 